\title{
Coplanar Waveguide-fed UWB Slotted Antenna with Notched-band Performance
}

\author{
Djelloul Aissaoui ${ }^{1,3,{ }^{*}}$, Abdelhalim Chaabane ${ }^{2}$, Ahcene Boualleg ${ }^{2}$, Mohammed Guerroui² \\ 1 Department of Electrical Engineering, Faculty of Science and Technology, University of Djelfa, P. O. B. 3117, Djelfa, Algeria \\ ${ }^{2}$ Laboratoire des Télécommunications-LT, Faculté des Sciences et de la Technologie, Université 8 Mai 1945 Guelma, P. O. B. 401 , \\ 24000 Guelma, Algeria \\ ${ }^{3}$ Telecommunication Laboratory, Faculty of Technology, University of Abou Bekr Belkaid Tlemcen, P. O. B. 230, Chetouane, \\ 13000 Tlemcen, Algeria \\ * Corresponding author, e-mail: djelloul.aissaoui@emt.inrs.ca
}

Received: 05 March 2020, Accepted: 09 June 2020, Published online: 22 January 2021

\begin{abstract}
Compact coplanar waveguide Ultra-wideband (UWB) monopole antenna with band notched characteristics is presented in this paper. The band rejection is achieved by etching a circular slot on the radiating patch. The antenna is printed on the FR4-Epoxy substrate with overall dimensions of $23.5 \times 31 \times 1.5 \mathrm{~mm}^{3}$. The measured results indicate that the antenna operates in the frequency range from 1.76 to $11.07 \mathrm{GHz}$ and rejects the band 2.42 to $5.37 \mathrm{GHz}$ with an acceptable measured input impedance over the whole operating frequency bandwidth. Furthermore, the simulated results indicate that the antenna exhibits stable radiation patterns with appreciable gain and efficiency over the whole operating band except at the notched-band. Accordingly, this antenna provides a good solution for wireless communication systems with good characteristics.
\end{abstract}

\section{Keywords}

UWB antenna, slot antenna, notched-band, reflection coefficient, voltage standing wave ratio, radiation patterns

\section{Introduction}

Ultra-wideband (UWB) communication systems have recently attracted great interest of scientists and engineers because they have several advantages such as high data transmission capacity, enormous available bandwidth, secure communications, low cost, low power consumption and multipath immunity [1-3]. They are broadly used in military, civilian, commercial, and medical applications. In 2002, the Federal Communication Commission (FCC) legalized the use of a large bandwidth of $7.5 \mathrm{GHz}$ from 3.1 to $10.6 \mathrm{GHz}$ band with low radiated power for commercial usage [4]. Since then, several UWB antennas have been designed that covers the UWB range $[5,6]$.

However, there still exist some other narrowband communication applications which may cause electromagnetic interference with the UWB band such as the worldwide interoperability for microwave access (WiMAX) and the Wireless Local Area Network (WLAN) [7]. To handle this problem, several techniques, recently reported in the literature, have been applied by using different techniques such as slot resonators, complementary split ring resonators, split ring resonators, parasitic strips, Defected Ground Structures (DGS) and integrating filters with antennas $[8,9]$.

In this paper, UWB antennas having notched-band will be presented giving their practical performance. To avoid the interferences with the other coexisting narrowband wireless systems operating in the UWB band, a circular slot is etched on the radiating patch to produce a notchedband. The simulations are achieved using commercial software CST Microwave studio ${ }^{\mathrm{TM}}[10]$.

\section{Antenna configuration}

Fig. 1 depicts the configuration of the proposed antenna. The overall size of the antenna is $23.5 \times 31 \mathrm{~mm}^{2}$. The proposed UWB antenna is designed using a dielectric substrate of FR4-Epoxy $\left(\varepsilon_{r}=4.4, \tan \delta=0.025\right)$ with thickness of $1.5 \mathrm{~mm}$. The lower border of the radiating patch is escalated for tuning the capacitive and inductive coupling 


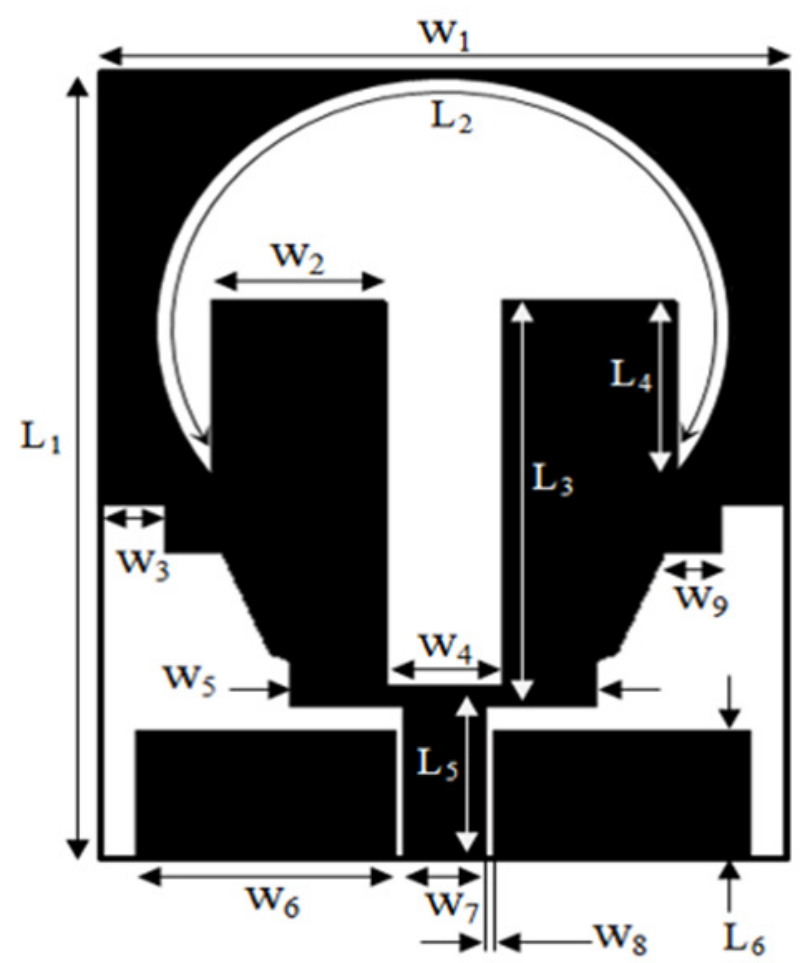

Fig. 1 Configuration of the proposed antenna.

between the radiating slotted patch and the ground plane. Consequently, an enhanced impedance matching and a larger impedance bandwidth can be achieved.

In order to avoid the interference with co-existing systems, a circular slot is etched inside the radiating patch to achieve a notched-band performance. Furthermore, a rectangular slit is introduced on the radiating patch attain the preferred miniaturization. The antenna design evolution is presented in the Fig. 2. All the optimized parameters of the proposed notched-band UWB antenna are depicted in Table 1.

To prevent the interference with co-existing systems, a circular slot acting as a single guided wavelength resonator is etched inside the rectangular radiating patch to produce a notched-band performance.

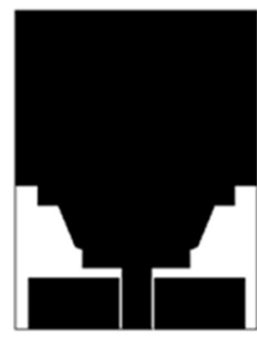

(a)

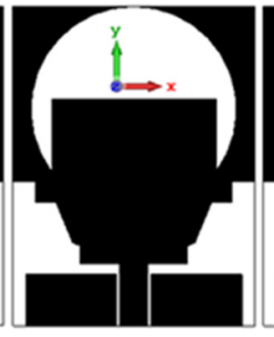

(b)

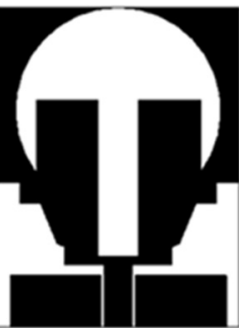

(c)
Fig. 2 Evaluation of the proposed UWB antenna with the application of the notched-band structure, (a) antenna 1, (b) antenna 2, (c) antenna 3.
Table 1 Optimized parameters of the proposed antenna

\begin{tabular}{lccc}
\hline Parameters & $\begin{array}{c}\text { Dimensions, } \\
\mathrm{mm}\end{array}$ & Parameters & $\begin{array}{c}\text { Dimensions, } \\
\mathrm{mm}\end{array}$ \\
\hline$W_{1}$ & 23.5 & $W_{9}$ & 1.98 \\
$W_{2}$ & 5.97 & $L_{1}$ & 31 \\
$W_{3}$ & 2.19 & $L_{2}$ & 44.36 \\
$W_{4}$ & 4 & $L_{3}$ & 16 \\
$W_{5}$ & 10.46 & $L_{4}$ & 6.97 \\
$W_{6}$ & 8.85 & $L_{5}$ & 6 \\
$W_{7}$ & 2.8 & $L_{6}$ & 5 \\
$W_{8}$ & 0.25 & $H$ & 1.5 \\
\hline
\end{tabular}

According to the other published works like [11], the frequency center of the notched-band can be calculated by the Eq. (1).

$$
f_{\text {notched band }} \approx \frac{c}{\lambda_{g} \sqrt{\left(\varepsilon_{r}+1\right) / 2}} \approx \frac{c}{L_{2} \sqrt{\left(\varepsilon_{r}+1\right) / 2}}
$$

Here $c$ denotes the speed of light in free space, $\lambda_{g}$ is the guided wavelength, $\varepsilon_{r}$ is the dielectric constant of the substrate, $L_{2}$ is the effective length of the etched slot.

Fig. 3 shows the surface current distribution on the proposed antenna at the notched-band center $3.87 \mathrm{GHz}$.

A high current density along the investigated circular slot was detected which makes the antenna non-reactive.

It is evident that the etched slot on the radiating patch is the responsible for producing the notched-band. This confirms that the proposed antenna cannot radiate effectively at the notch band. Accordingly, the etched circular slot inhibits the surface current and consequently a rejected band is achieved.

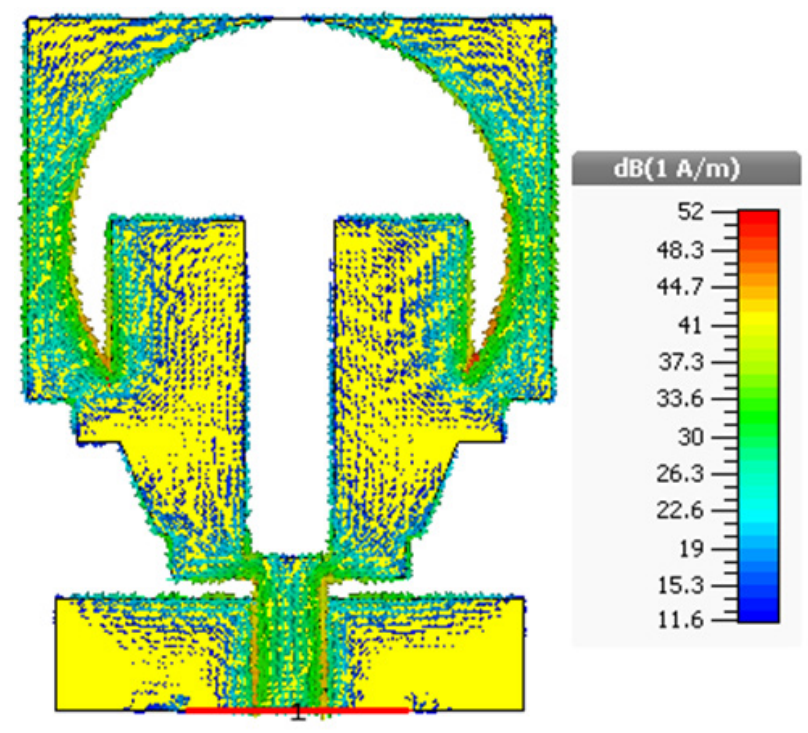

Fig. 3 Current distribution on the proposed antenna at $3.87 \mathrm{GHz}$. 
Moreover, a poor current flowed along the rectangular slit is observed indicates a nil contribution of this etched slit on the low frequencies and of the production of the notchedband. Hence, the rectangular slit helps to minimize the conductor losses and to reduce the weight of the antenna which is especially enviable from the miniaturization viewpoint.

\section{Results and discussion}

The fabricated antenna is presented in Fig. 4. A comparison of the Voltage Standing Wave Ratio (VSWR) of the antenna, with and without slots (Fig. 2), is presented in Fig. 5 which confirms that the circular slot is the responsible for producing the notched-band function and prove the nil contribution of the etched rectangular slit on the production of the notched-band.

The VSWR of the proposed coplanar waveguide fed band notched UWB antenna was measured using the R\&S®ZNB Vector Network Analyzer. From the experimental results (Fig. 6) the impedance bandwidth is ranging from 1.76 to $11.07 \mathrm{GHz}$ with a rejected band from 2.42 to $5.37 \mathrm{GHz}$. The slight mismatch between the simulated and the measured may be assigned to the tolerance in the realization and in the measurement, SMA connector effects and of the soldering, and to the external electromagnetic disturbances which were not taken into consideration in the simulations. Except at the notched-band, the measured impedance matching is acceptable over all the operating frequency band, which signifies the broadband characteristics of the proposed antenna.

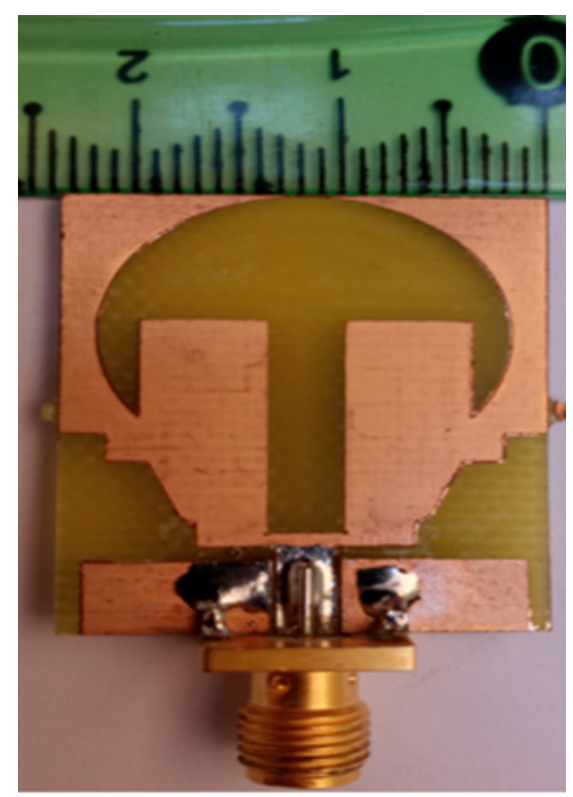

Fig. 4 Fabricated prototype of the proposed UWB antenna.

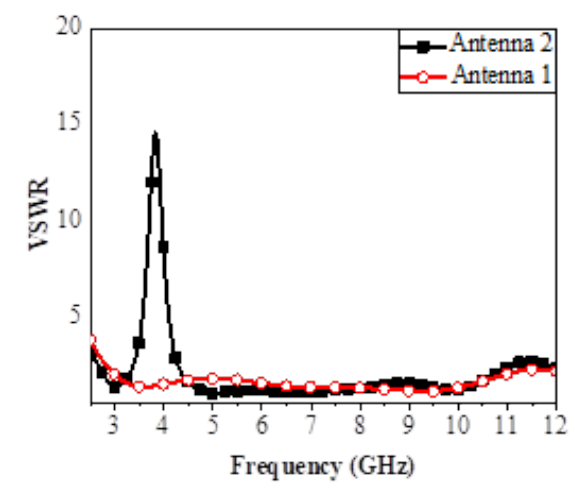

(a)

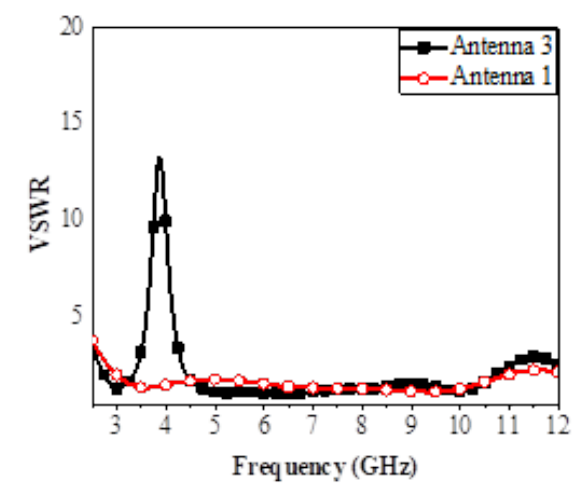

(b)

Fig. 5 VSWR comparisons for the antennas with and without slots, (a) between antenna 1 and 2, (b) between antenna 1 and 3 .

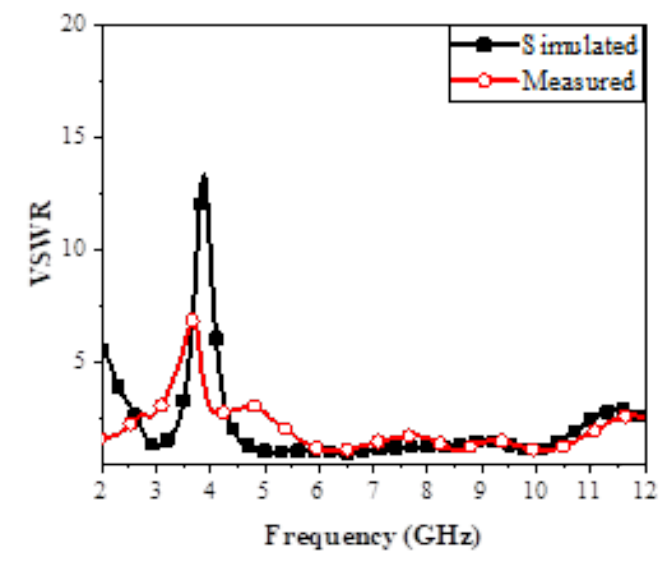

Fig. 6 Measured and simulated VSWR of the proposed UWB notched-band antenna.

Fig. 7 presents the measured real and imaginary input impedance of the proposed slotted antenna. As it is exhibited, there is impedance mismatch at the notchedband. This means that the antenna is preventing the wave at notched-band which results in steep rise of the reflection coefficient. 


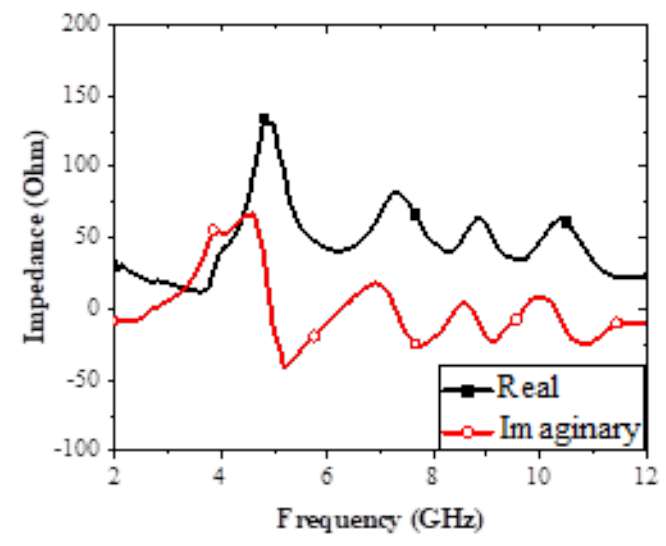

Fig. 7 Measured real and imaginary impedance.

The simulated normalized radiation patterns for the proposed antenna in both the $x z$-plane (H-plane) and the $y z$-plane (E-plane) over three frequencies 3, 6 and $10 \mathrm{GHz}$ are represented in Fig. 8. Omnidirectional radiation patterns are obtained in the $H$-plane and bidirectional radiation patterns in the $E$ plane over the entire pass bands; for the reason of placing a small ground plane on the same side of the radiating patch, similar appearances are noted in [12]. At a higher frequency, the radiation patterns still retain excellent

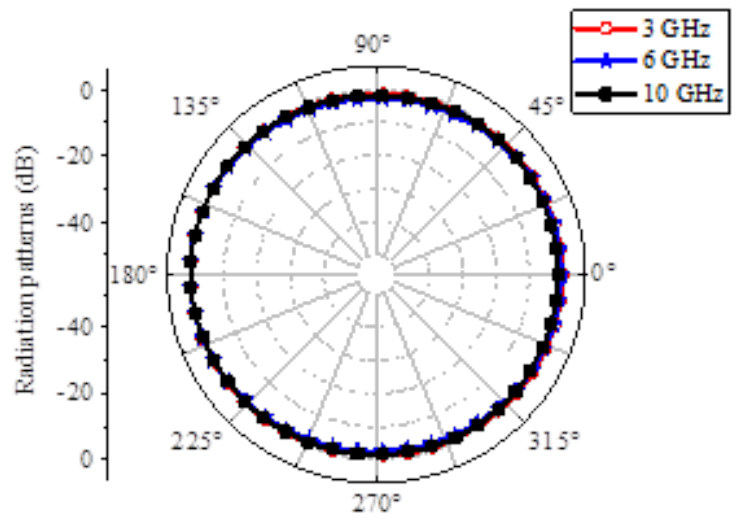

(a)

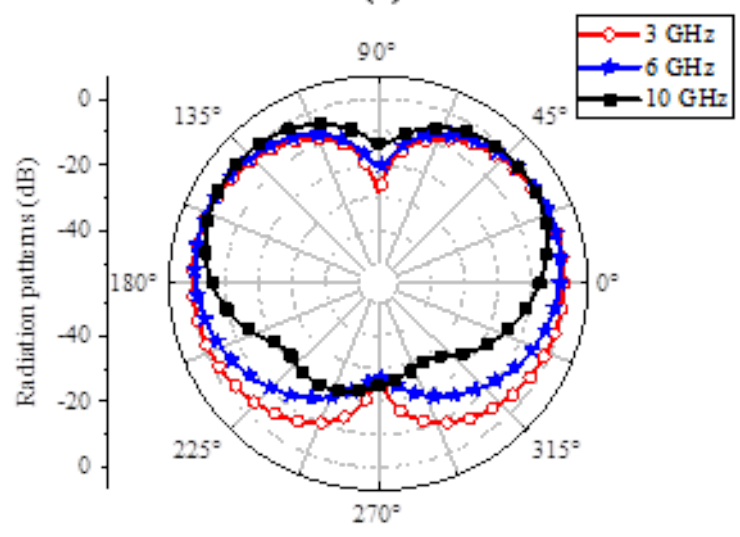

(b)

Fig. 8 Normalized radiation patterns at different frequencies, (a) $x z$-plane, (b) $y z$-plane. omnidirectional curves on the $H$-plane, whereas, a low distortion can be observed for the $E$ plane at $10 \mathrm{GHz}$. It can be observed that the realized gain of the proposed slotted UWB antenna drop dramatically at the band-notched frequency and have reasonable values away from outwards that are better than the ones achieved in [13-16]. Furthermore, except at the notched-band a good radiation efficiency is achieved; that is almost over $90 \%$ on the whole working bandwidth of the proposed antenna as depicted in the Fig. 9; similar appearances is achieved in [17].

Moreover, it sharply reduces to $56.52 \%$ at the frequency center of the notched-band proving an excellent band-notched performance of the proposed UWB slotted antenna. The dramatic drop of the antenna gain and radiation efficiency means that most of the power fed into the proposed UWB slotted antenna is reflected back. Consequently, this slotted UWB antenna is powerful candidate for UWB applications and is very appropriate for several wireless communication systems.

\section{Conclusion}

A compact coplanar waveguide-fed UWB slotted monopole antenna with stop band has been discussed in this paper. The stop band performance is achieved by etching a circular slot from the radiating patch. The antenna has a compact size of $23.5 \times 31 \times 1.5 \mathrm{~mm}^{3}$. The measured results indicate that it is operating in the frequency range from 1.76 to $11.07 \mathrm{GHz}$ and rejects the band 2.42 to $5.37 \mathrm{GHz}$ with a satisfactory measured input impedance over the operating frequency bandwidth. Moreover, the simulated results show that the antenna display stable radiation patterns, acceptable realized gain and a good radiation efficiency which confirm that the antenna can be a good candidate for wireless communication systems.

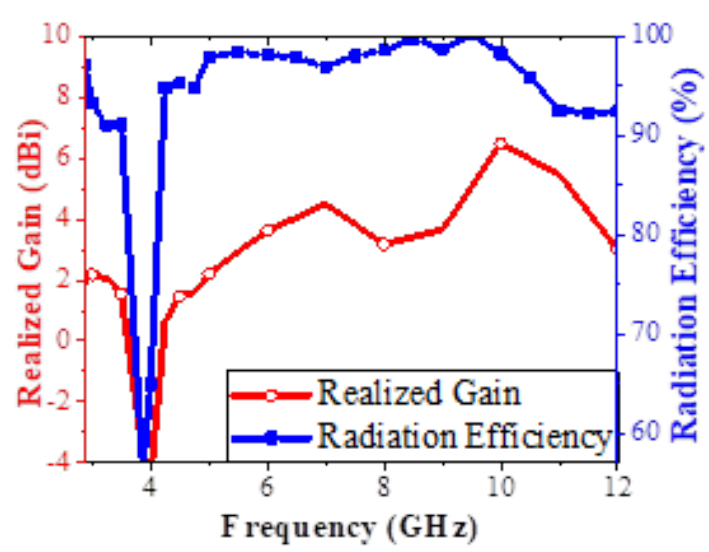

Fig. 9 Realized gain and Radiation efficiency achieved by the proposed antenna. 


\section{References}

[1] Chaabane, A., Babouri, A. "Dual Band Notched UWB MIMO Antenna for Surfaces Penetrating Application", Advanced Electromagnetics, 8(3), pp. 6-15, 2019. https://doi.org/10.7716/aem.v8i3.1062

[2] Rahman, M. "CPW Fed Miniaturized UWB Tri-Notch Antenna with Bandwidth Enhancement", Advances in Electrical Engineering, 2016, Article ID: 7279056, 2016. https://doi.org/10.1155/2016/7279056

[3] Rahman, M., Nagshvarian Jahromi, M., Mirjavadi, S. S., Hamouda, A. M. "Compact UWB Band-Notched Antenna with Integrated Bluetooth for Personal Wireless Communication and UWB Applications", Electronics, 8(2), Article Number: 158, 2019. https://doi.org/10.3390/electronics8020158

[4] Federal Communications Commission "Revision of Part 15 of the Commission's Rules Regarding Ultra-Wideband Transmission Systems", Federal Communications Commission, Washington, DC, USA, Rep. FCC 02-48, 2002. [online] Available at: https://www.fcc. gov/document/revision-part-15-commissions-rules-regarding-ultrawideband-7 [Accessed: 08 February 2020]

[5] Aissaoui, D., Abdelghani, L. M., Boukli-Hacen, N., Denidni, T. A. "CPW-fed UWB hexagonal shaped antenna with additional fractal elements", Microwave and Optical Technology Letters, 58(10), pp. $2370-2374,2016$ https://doi.org/10.1002/mop.30053

[6] Ellis, M. S., Zhao, Z., Wu, J., Nie, Z., Liu, Q. H. "Small planar monopole ultra-wideband antenna with reduced ground plane effect", IET Microwaves, Antennas \& Propagation, 9(10), pp. 1028-1034, 2015. https://doi.org/10.1049/iet-map.2014.0538

[7] Habash, M. F., Tantawy, A. S., Atallah, H. A., Abdel-Rahman, A. B. "Compact Size Triple Notched-bands UWB Antenna with Sharp Band-Rejection Characteristics at WiMAX and WLAN Bands", Advanced Electromagnetics, 7(3), pp. 99-103, 2018. https://oi.org/10.7716/aem.v7i3.820

[8] Atallah, H. A., Abdel-Rahman, A. B., Yoshitomi, K., Pokharel, R. K. "CPW-Fed UWB antenna with sharp and high rejection multiple notched bands using stub loaded meander line resonator", AEU International Journal of Electronics and Communications, 83, pp. $22-31,2018$. https://doi.org/10.1016/j.aeue.2017.08.022

[9] Satyanarayana, B., Mulgi, S. "Design of planar band-notched monopole antenna for $2.4 \mathrm{GHz}$ WLAN and UWB applications", Microwave and Optical Technology Letters, 57(11), pp. 2496-2501, 2015

https://doi.org/10.1002/mop.29376
[10] CST Microwave Studio "Computer Simulation Technologie, version 2016", [computer program] Available at: https://www.3ds. $\mathrm{com} / \mathrm{fr} /$ produits-et-services/simulia/produits/cst-studio-suite/ [Accessed: 08 February 2020]

[11] Arshed, T., Tahir, F. A. "A miniaturized triple band-notched UWB antenna", Microwave and Optical Technology Letters, 59(10), pp. 2581-2586, 2017. https://doi.org/10.1002/mop.30787

[12] Garg, R. K., Nair, M. V. D., Singhal, S., Tomar, R. "A new type of compact ultra-wideband planar fractal antenna with WLAN band rejection", Microwave and Optical Technology Letters, 62(7), pp. 2537-2545, 2020. https://doi.org/10.1002/mop.32304

[13] Zeng, Y., Zhang, H., Zhang, Y., Zhao, H. "Compact Band-Notched UWB Antenna Based on CSRR for WiMAX/WLAN Applications", In: 2018 International Conference on Microwave and Millimeter Wave Technology (ICMMT), Chengdu, China, 2018, pp. 1-3. https://doi.org/10.1109/ICMMT.2018.8563741

[14] Sharma, P., Vyas, K., Yadav, R. P. "Design and analysis of miniaturized UWB antenna with tunable notched band", International Journal of Microwave and Wireless Technologies, 9(3), pp. 691-696, 2017. https://oi.org/10.1017/S1759078716000489

[15] Peng, H., Wang, C., Zhao, L., Liu, J. "Novel SRR-loaded CPWfed UWB antenna with wide band-notched characteristics", International Journal of Microwave and Wireless Technologies, 9(4), pp. 875-880, 2017. https://oi.org/10.1017/S1759078716000702

[16] Shareef, W. Z., Ismail, A., Alhawari, A. R. H. "Substrate-perforated and compact ultra-wideband antenna with WLAN band rejection", International Journal of Microwave and Wireless Technologies, 7(5), pp. 543-550, 2015. https://doi.org/10.1017/S1759078714000786

[17] Mandal, S., Karmakar, A., Singh, H., Mandal, S. K., Mahapatra, R., Mal, A. K. "A miniaturized CPW-fed on-chip UWB monopole antenna with band-notch characteristics", International Journal of Microwave and Wireless Technologies, 12(1), pp. 95-102, 2020. https://oi.org/10.1017/S1759078719000941 